University of Wollongong

Research Online

Australian Institute for Innovative Materials -

Papers

Australian Institute for Innovative Materials

$1-1-2017$

\title{
Reverse Microemulsion Synthesis of Sulfur/Graphene Composite for Lithium/Sulfur Batteries
}

Mohammad Kaiser

University of Wollongong, mrk912@uowmail.edu.au

Zhaohui Ma

University of Maryland

Xiwen Wang

University of Maryland

Fudong Han

University of Maryland

Tao Gao

University of Maryland

See next page for additional authors

Follow this and additional works at: https://ro.uow.edu.au/aiimpapers

Part of the Engineering Commons, and the Physical Sciences and Mathematics Commons

Research Online is the open access institutional repository for the University of Wollongong. For further information contact the UOW Library: research-pubs@uow.edu.au 


\title{
Reverse Microemulsion Synthesis of Sulfur/Graphene Composite for Lithium/ Sulfur Batteries
}

\author{
Abstract \\ Due to its high theoretical capacity, high energy density, and easy availability, the lithium-sulfur (Li-S) \\ system is considered to be the most promising candidate for electric and hybrid electric vehicle \\ applications. Sulfur/carbon cathode in Li-S batteries still suffers, however, from low Coulombic efficiency \\ and poor cycle life when sulfur loading and the ratio of sulfur to carbon are high. Here, we address these \\ challenges by fabricating a sulfur/carboxylated-graphene composite using a reverse (water-in-oil) \\ microemulsion technique. The fabricated sulfur-graphene composite cathode, which contains only 6 wt \% \\ graphene, can dramatically improve the cycling stability as well as provide high capacity. The \\ electrochemical performance of the sulfur-graphene composite is further enhanced after loading into a \\ three-dimensional heteroatom-doped (boron and nitrogen) carbon-cloth current collector. Even at high \\ sulfur loading ( $8 \mathrm{mg} / \mathrm{cm} 2$ ) on carbon cloth, this composite showed $1256 \mathrm{mAh} / \mathrm{g}$ discharge capacity with \\ more than $99 \%$ capacity retention after 200 cycles.

\section{Disciplines} \\ Engineering | Physical Sciences and Mathematics

\section{Publication Details} \\ Kaiser, M. Rejaul., Ma, Z., Wang, X., Han, F., Gao, T., Fan, X., Wang, J., Liu, H. Kun., Dou, S. \& Wang, C. \\ (2017). Reverse Microemulsion Synthesis of Sulfur/Graphene Composite for Lithium/Sulfur Batteries. \\ ACS Nano, 11 (9), 9048-9056.

\section{Authors} \\ Mohammad Kaiser, Zhaohui Ma, Xiwen Wang, Fudong Han, Tao Gao, Xiulin Fan, Jiazhao Wang, Hua-Kun \\ Liu, Shi Xue Dou, and Chunsheng Wang
}




\title{
Reverse Microemulsion Synthesis of
}

\section{Sulfur/Graphene Composite for Lithium/Sulfur}

\section{Batteries}

Mohammad Rejaul Kaiser ${ }^{a, b}$, Zhaohui Ma ${ }^{a}$, Xiwen Wang ${ }^{a}$, Fudong Han ${ }^{a}$, Tao Gao ${ }^{a}$, Xiulin Fan $^{a}, J_{i a-Z h a o}$ Wang $^{b}$, Hua Kun Liu ${ }^{b}$, Shixue Dou ${ }^{b}$ and Chunsheng Wang ${ }^{a *}$

${ }^{a}$ Department of Chemical and Biomolecular Engineering, University of Maryland, College Park, Maryland, 20742, United States

${ }^{\mathrm{b}}$ Institute for Superconducting and Electronic Materials, University of Wollongong, Wollongong, NSW 2522, Australia

\section{KEYWORDS}

reverse microemulsion, surfactants, sulfur solubility, carbooxylated graphene, functionalized carbon cloth, sulfur cathode.

\begin{abstract}
Due to its high theoretical capacity, high energy density, and easy availability, the lithium-sulfur (Li-S) system is considered to be the most promising candidate for electric and hybrid electric vehicle applications. Sulphur/carbon cathode in Li-S batteries still suffers, however, from low coulombic efficiency and poor cycle life when sulfur loading and the ratio of sulfur to carbon are
\end{abstract}


high. Here, we address these challenges by fabricating a sulfur/carboxylated-graphene composite using a reverse (water-in-oil) microemulsion technique. The fabricated sulfur-graphene composite cathode, which contains only $6 \mathrm{wt} \%$ graphene, can dramatically improve the cycling stability as well as providing high capacity. The electrochemical performance of the sulfurgraphene composite is further enhanced after loading into a three-dimensional heteroatom-doped (boron and nitrogen) carbon-cloth current collector. Even at high sulfur loading $\left(\sim 8 \mathrm{mg} / \mathrm{cm}^{2}\right)$ on carbon cloth, this composite showed $1256 \mathrm{mAh} / \mathrm{g}$ discharge capacity with more than $99 \%$ capacity retention after 200 cycles.

Li-ion batteries have been dominant over other battery systems for portable devices (e.g. smart phones, laptop computers, cameras, etc.), but they barely can meet the energy and power requirements for electric and hybrid electric vehicles. ${ }^{1}$ The current Li-ion batteries can deliver gravimetric energy density of $160-$ $190 \mathrm{Wh} / \mathrm{kg}$, which can, at most, run an electric vehicle for 150 to $200 \mathrm{~km}$. The main hurdle for low energy density Li-ion batteries comes from their transition metal oxide cathodes, which can only deliver a theoretical capacity of $150-170 \mathrm{mAh} / \mathrm{g} .{ }^{2}$

Sulfur, which exhibits $2600 \mathrm{Wh} \cdot \mathrm{kg}^{-1}$ specific energy when coupled with lithium, is inexpensive, naturally abundant, and environmentally benign, so it could be a better and more promising alternative to the existing transition metal oxide cathode materials. Even though the $\mathrm{Li} / \mathrm{S}$ system has been under investigation for the last thirty years, it is yet to be commercialized ${ }^{3}$ due to three main challenges: (i) the very low electrical and ionic conductivities of sulfur, leading to limited active material utilization; (ii) dissolution into the electrolyte of long chain polysulfides and the polysulfide shuttle, which causes low cycling stability; and (iii) volume changes in the active material during charge and discharge, which causes degradation of the cathode. Extensive research has been conducted on loading sulfur onto different conductive carbon materials, ${ }^{4-8}$ in combination with different electrolytes,,${ }^{9-10}$ binders, ${ }^{11-12}$ and additives. ${ }^{13-}$ 
${ }^{17}$ In most cases, a high initial capacity (> $1000 \mathrm{mAh} / \mathrm{g}$ ) was achieved, but the capacity still gradually decays with charge/discharge cycling.

Graphene, along with its derivatives (reduced graphene, functionalized graphene, heteroatom doped graphene, etc.), has high electronic conductivity and high surface area, and is considered one of the most promising carbons to ameliorate the challenges of the $\mathrm{Li} / \mathrm{S}$ system. ${ }^{18-20}$ Considerable research has been conducted on graphene/sulfur composites to increase the capacity and stability of the Li/S system. In most cases, however, the graphene/sulfur composites were fabricated either by mechanical milling or by chemical precipitation methods, ${ }^{19,21-22}$ where the graphene was not exfoliated or firmly adhered to the sulfur, thus requiring a high ratio of graphene to sulphur to physically separate the sulfur from the liquid electrolyte. To improve the cycling performance and stability, it is important to have better adhesion between the sulfur/sulfide and the graphene, and they need to be uniformly mixed each other with a high sulphur loading, which will not only help the overall capacity, but also will maintain the structural integrity during expansion and contraction of the sulfur. It is hard, however, to synthesize such a graphene/sulphur nanocomposite using traditional technologies.

The water-in-oil microemulsion (w/o microemulsion) or reverse microemulsion method, commonly used for the synthesis of uniform composite nanoparticles from their salt solutions, ${ }^{23-24}$ can be used for the synthesis of graphene/sulphur nanoparticles with strong adhesion in the sulfur/sulfide carboxyl functionalized graphene. In the w/o microemulsion or reverse microemulsion method, an aqueous solution containing metal salts is dispersed in an organic oil phase with the help of a surfactant, and this microemulsion is designated as microemulsion-1, while another microemulsion (designated as microemulsion-2) is prepared, in which an aqueous solution containing a reducing agent is dispersed in the same organic oil phase. Then, these two emulsions are mixed together, and the aqueous phases merge and react with each other to form metal or composite nanoparticles. ${ }^{24}$ Microemulsions have been used by the scientific community for the last sixty years in different fields, ${ }^{25-27}$ but they are yet to be used for the synthesis of sulfur/carbon composites. This is because the synthesized sulfur from the reverse 
microemulsion method is a nonpolar molecule and dissolves in almost all the organic nonpolar solvents that generally have been used as the oil phase in the reverse microemulsion method. Herein, we used sulfur-dissolved saturated cyclohexane (sulfur solubility of $1.185 \mathrm{wt} \%$ ) as the oil phase, so that the synthesized sulfur could not dissolve in the cyclohexane. We synthesized our sulfur/graphene composite with a $94 \% \mathrm{~S}$ ratio by mixing two emulsions to form graphene-coated/adhered sulfur, in which microemulsion-1 was synthesized by adding an aqueous carboxylated graphene - sodium polysulfide suspension solution into cyclohexane oil as, while microemulsion-2, was synthesized by adding an aqueous solution of hydrochloric acid into cyclohexane. With an electrode consisting of S/C composite on a three-dimensional (3-D) heteroatom-doped carbon-cloth current collector (loading of active materials 8 $\left.\mathrm{mg} / \mathrm{cm}^{2}\right), 1256 \mathrm{mAh} / \mathrm{g}$ discharge capacity was obtained with more than $99 \%$ capacity retention after 200 cycles.

\section{RESULTS AND DISCUSSION:}

\section{Reverse microemulsion and selection of materials}

A dispersion consisting of water, oil, and surfactant(s) is an isotropic and thermodynamically stable system. A dispersion with a domain diameter of $\sim 1$ to $100 \mathrm{~nm}$ is called a microemulsion. If the dispersed phase is water or an aqueous solution and the continuous phase is an organic liquid (an "oil"), it is called a water-in-oil (w/o) microemulsion or reverse microemulsion. ${ }^{28}$ In our method, $2 \mathrm{M} \mathrm{Na}_{2} \mathrm{~S}_{x}$ solution mixed with carboxylated graphene was used as the aqueous phase. The carboxylated graphene can form hydrogen bonds with water, which helps to uniformly disperse the graphene in the water, while $\mathrm{Na}_{2} \mathrm{~S}_{x}$ can reacts with $\mathrm{HCl}$ to form hydrogen sulfide $\left(\mathrm{H}_{2} \mathrm{~S}\right)$ and sodium chloride $(\mathrm{NaCl})$, where the $\mathrm{H}_{2} \mathrm{~S}$ gas cannot affect the ratio of aqueous phase to oil phase. $\mathrm{Na}_{2} \mathrm{~S}_{2} \mathrm{O}_{3}$, which is low-cost, widely available, and generally used to synthesize the sulfur chemically, produces $\mathrm{H}_{2} \mathrm{O}$ as a by-product. This extra water will cause an imbalance in the ratio of aqueous phase to oil phase, and hence, $\mathrm{Na}_{2} \mathrm{~S}_{2} \mathrm{O}_{3}$ has been avoided in our work. 
Table 1. Solubility of sulfur in common organic solvents. ${ }^{29}$

\begin{tabular}{|c|c|c|c|c|c|c|c|}
\hline Solvent & $\begin{array}{c}\text { Solubility } \\
\text { (wt\%) }\end{array}$ & Solvent & $\begin{array}{c}\text { Solubility } \\
(w t \%)\end{array}$ & Solvent & $\begin{array}{c}\text { Solubility } \\
(w t \%)\end{array}$ & Solvent & $\begin{array}{c}\text { Solubility } \\
\text { (wt \%) }\end{array}$ \\
\hline Ethanol & 0.066 & n-Hexane & 0.400 & Acetone & 0.079 & Aniline & 1.259 \\
\hline $\begin{array}{l}\text { Carbon } \\
\text { tetrachloride }\end{array}$ & 0.832 & Xylene & 2.051 & Nitrobenzene & 0.856 & Diethyl ether & 0.181 \\
\hline Cyclohexane & 1.185 & Toluene & 2.070 & Chloroform & 1.164 & Chlorobenzene & 2.370 \\
\hline Benzene & 2.093 & $\begin{array}{l}\text { Carbon-di- } \\
\text { sulfide }\end{array}$ & 34.800 & $\begin{array}{c}\text { Diethyl } \\
\text { formamide }\end{array}$ & 0.191 & Bromoform & 3.640 \\
\hline
\end{tabular}

The oil phase must be nonpolar, hydrophobic, and feature extremely low solubility of sulfur. In addition, the oil must have very good compatibility with the surfactant and co-surfactant to produce a uniform microemulsion. No organic oil can fulfil all these requirements. Table 1 shows the solubility limits of sulfur in common organic solvents, and the left column shows the solubility of sulfur in nonpolar solvents apart from ethanol. Among them, carbon tetrachloride and n-hexane show low solubility of sulfur, but they cannot form a stable and uniform microemulsion. Cyclohexane, which has $1.185 \mathrm{wt} \%$ solubility of sulfur, can form an extremely stable and uniform microemulsion with sorbitan monooleate (Span $\left.{ }^{\circledR} 80\right)$ and polyethylene glycol (PEG-20) sorbitan monooleate (Tween ${ }^{\circledR} 80$ ) surfactants. ${ }^{30}$ These two surfactants have very low surface tension, with a hydrophilic-lipophilic balance (HLB) of 4.3 and 15 , respectively. A lower HLB number indicates higher hydrophobicity and vice-versa. In the reverse microemulsion method, a large amount of oil and small amount of water are generally used, and because of that, a ratio of 8:1 of Span80 and Tween80 surfactants was used in $450 \mathrm{ml}$ of cyclohexane. Moreover, it was found that, to form a stable reverse microemulsion, the HLB of the surfactant should be in the range of 3 to $6 .{ }^{31}$ Figure 1 presents a schematic illustration of the preparation of the reverse microemulsions and the synthesis of the sulfur-graphene composite from these emulsions, where the cyclohexane was saturated with sulfur before it was used as an oil phase. Photographs of the products in the reverse microemulsion method and synthesis of the sulfur-graphene composite are shown in Figure S1 in the Supporting Information. 

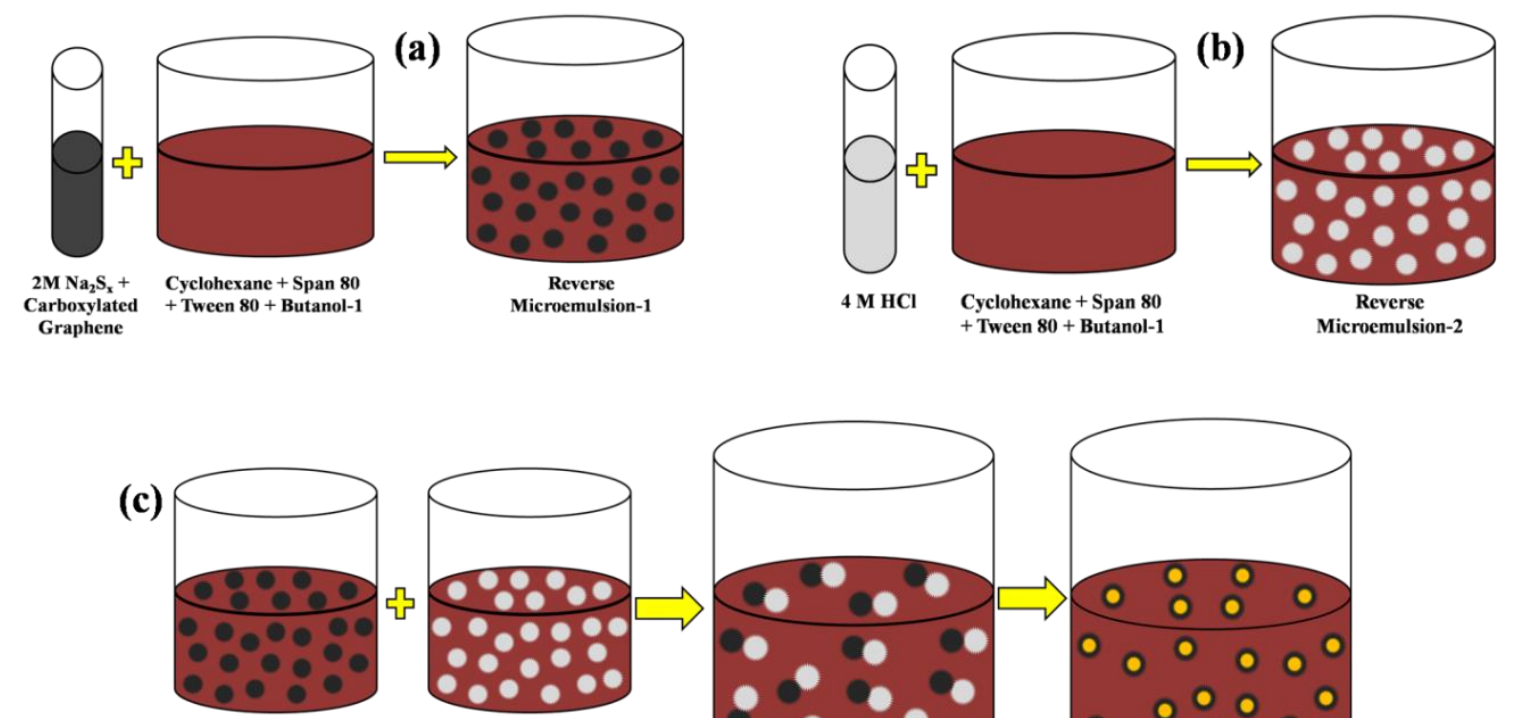

Reverse

Microemulsion-1
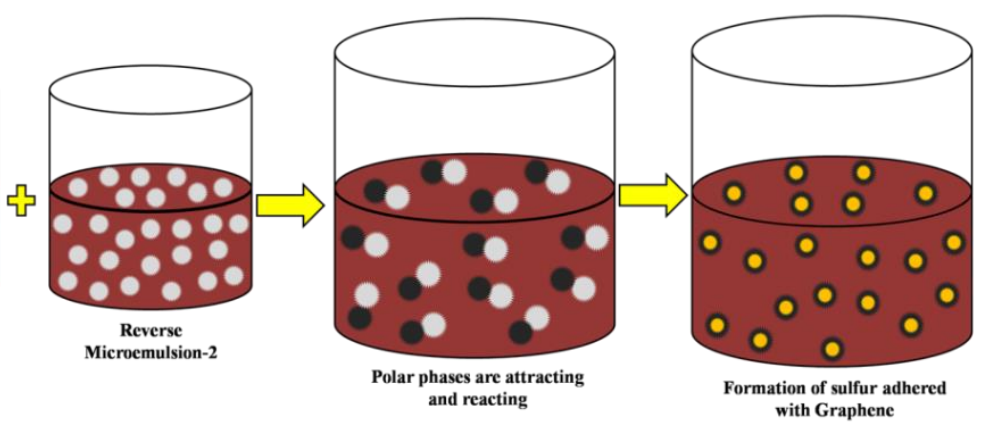

Figure 1. Schematic illustration of the reverse microemulsion method: a) preparing microemulsion-1, b) preparing microemulsion-2, and c) synthesis of sulfur/graphene composite.

The nanosized sulfur synthesized using the reverse microemulsion method has better adhesion to carboxylated graphene, improving the electronic conductivity and utilization of the sulfur in the electrode. Moreover, carboxyl functional groups on graphene can attract polysulfides, thus reducing the polysulfide shuttle reactions. The graphene content in our sulfur/graphene composite is $6.1 \mathrm{wt} \%$, which was measured by thermogravimetric analysis (TGA) (Figure S2). The conductivity of the synthesized composite, along with those of carboxylated graphene, commercial sulfur, and hand-mixed sulfur-graphene composite with the same weight percent of graphene, was measured with a four probe Signatone conductivity tester, and the results are shown in Table 2. 
Table 2. Electronic conductivity of sulfur-based materials.

\begin{tabular}{lccc}
\hline Sample & $\begin{array}{c}\text { Conductivity } \\
\text { S/cm }\end{array}$ & Sample & $\begin{array}{c}\text { Conductivity } \\
\text { S/cm }\end{array}$ \\
\hline Pure Sulfur & $3.32 \times 10^{-25}$ & $\begin{array}{c}\text { Reverse microemulsion } \\
\text { sulfur-graphene (RM-S/G) } \\
\text { composite }\end{array}$ & $7.92 \times 10^{4}$ \\
Carboxylated graphene & $4.09 \times 10^{6}$ & $\begin{array}{c}\text { Hand-mixed sulfur-graphene } \\
\text { composite }\end{array}$ & $3.27 \times 10^{2}$ \\
\hline
\end{tabular}

As shown in Table 2, the conductivity of the RM-S/G composite is two orders of magnitude higher than that of hand-mixed sulfur-graphene composite with the same composition. The increased conductivity of $\mathrm{RM}-\mathrm{S} / \mathrm{G}$ is due to better adhesion and exfoliation of graphene in the sulfur and the uniform distribution of sulfur on graphene. The particle size and morphology of the synthesized RM-S/G were characterized using scanning electron microscopy (SEM). As shown in Figure $2 \mathrm{a}$ and $2 \mathrm{~b}$, the graphene firmly adheres to the sulfur, forming 10 to $20 \mu \mathrm{m} \mathrm{S} / \mathrm{G}$ composite particles. It has been reported that the cyclohexane, Span 80 , and Tween 80 system is one of the most stable microemulsions with uniform micelle size ${ }^{30}$. The size of the micelles synthesized using Span 80 and Tween 80 in cyclohexane oil is approximately 7 to 100 $\mathrm{nm}^{30}$, which is much smaller than the sizes of the $\mathrm{S} / \mathrm{G}$ composite particles. It is possible that 10 to $20 \mu \mathrm{m}$ sulfur particles are induced by agglomeration of nanoscale sulfur during the nucleation and growth.

Figure $2 \mathrm{c}$ and $2 \mathrm{~d}$ shows transmission electron microscope (TEM) micrographs of the RM-S/G composite. It is clear that the crystalline graphene sheets, which have a moiré pattern, are exfoliated and welldistributed inside the sulfur particles. The graphene that is trapped inside the big sulfur particles demonstrates that the sulfur particles are agglomerated from graphene-coated sulfur nanoparticles during the nucleation and growth process. 


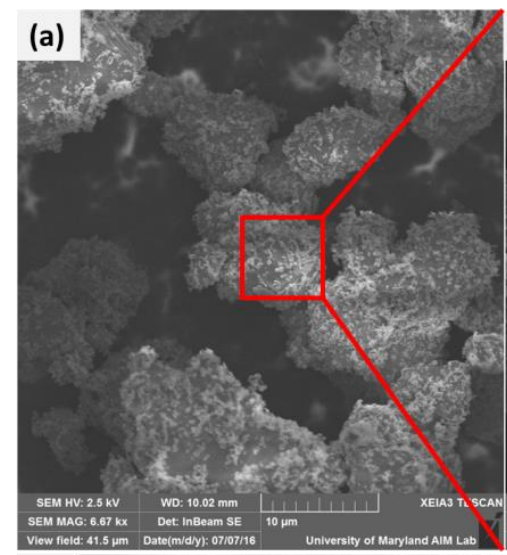

\section{(b)}

(c)

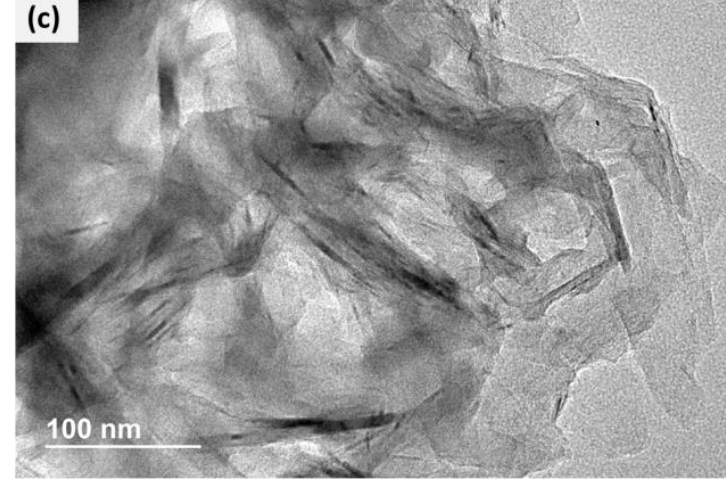

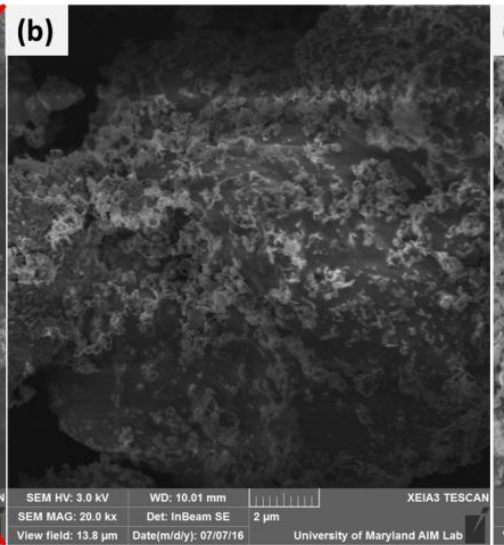

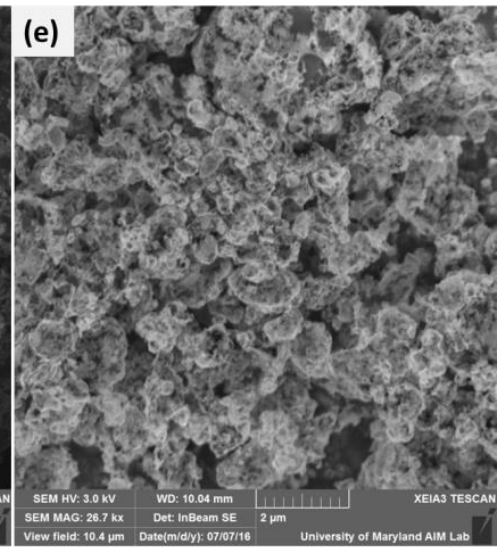

(d)

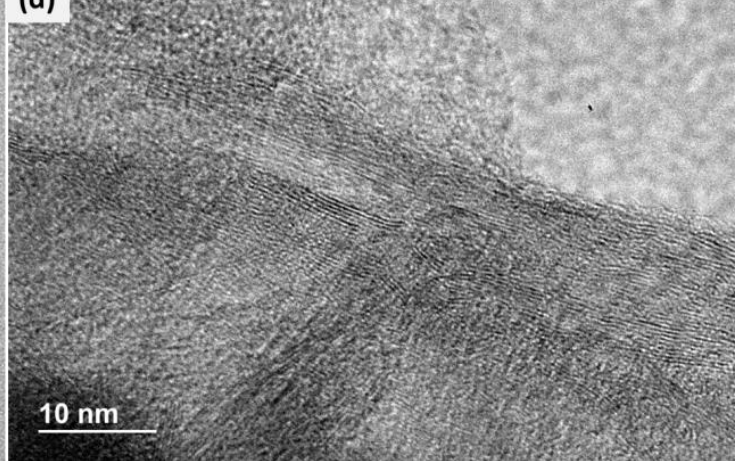

Figure 2. SEM and TEM micrographs of RM-S/G: a, b) SEM images of the as-synthesized composite at different magnifications; c, d) TEM micrographs that prove the presence and exfoliation of graphene inside the sulfur; and e) SEM image of ball-milled RM-S/G composite.

To further confirm the entrapment of graphene inside the sulfur, a sample of microsized sulfur/graphene composite was ball-milled (in the presence of isopropanol at $300 \mathrm{rpm}$ ), so that all the graphene sheets that were entrapped inside the sulfur particles could be exposed. The SEM micrograph of RM-S/G composite in Figure 2e shows the morphology of the sulfur/graphene composite after the ball milling, where smaller sized sulfur/graphene composite particles are observed. Each smaller particle contains carboxylated graphene sheets adhering to the sulfur particles that have been exposed after ball milling. It can be deduced from this that the large particles shown in Figure $2 \mathrm{~b}$ are mainly composed of smaller sized sulfur/graphene composite particles. 

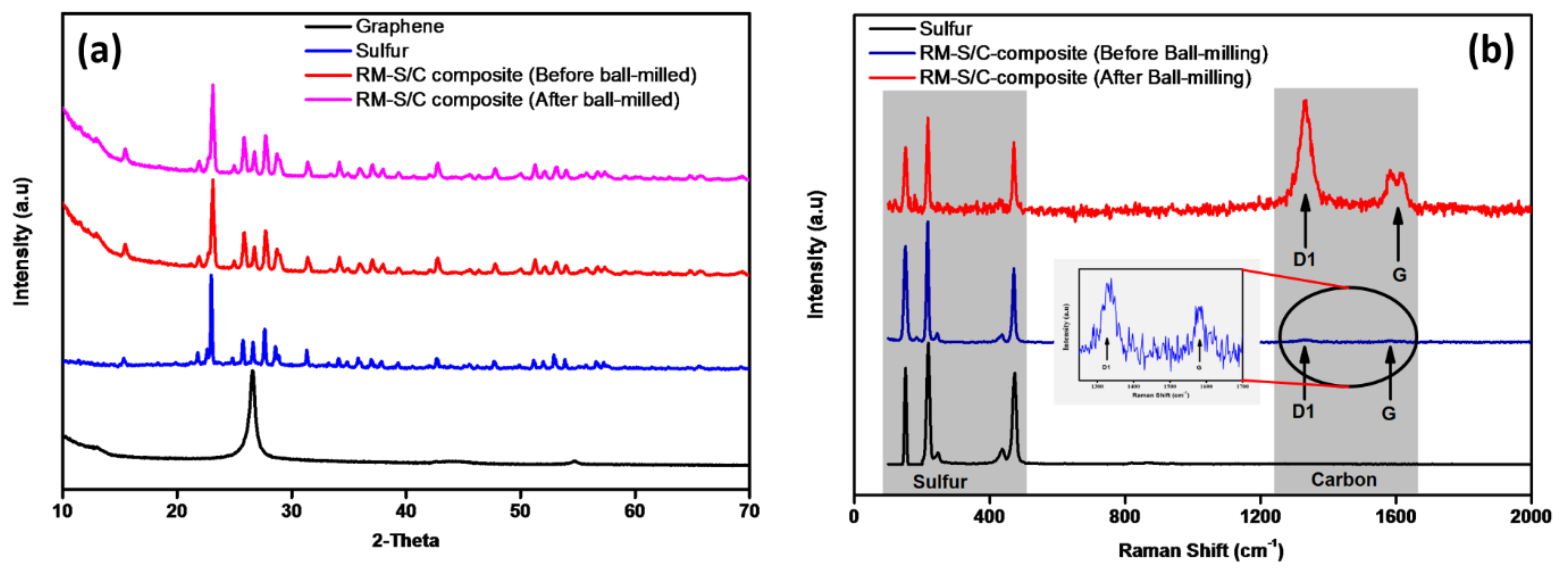

Figure 3. XRD patterns (a) and Raman spectra (b) of RM-S/G composite before and after ball milling.

The phase structure of RM-S/G composite along with that of graphene was characterized using X-ray diffraction (XRD, Figure 3a). Along with other small peaks, RM-S/G exhibits a characteristic peak of crystalline octa-sulfur $\left(\mathrm{S}_{8}\right)$ at around $23.1^{\circ}$ that is diffracted from the (222) planes. This characteristic peak at $23.1^{\circ}$ is broadened for RM-S/G composite compared to commercial sulfur, which indicates the smaller particle size of sulfur. Nevertheless, no significant peak broadening occurs after the ball milling of RM-S/G composite, which means that the crystallite size remains same and that the disparity of particle sizes is due to the physical adhesion of micro- and nano-sized particles. The Raman spectra of pure sulfur and RM-S/G composite are presented in Figure 3b, and all the spectra show sharp peaks at $219.1 \mathrm{~cm}^{-1}$ and $473.2 \mathrm{~cm}^{-1}$, which reflect the bending and the stretching of nonpolar S-S bonds, respectively. ${ }^{32}$ Moreover, RM-S/G composite shows small peaks around $1400 \mathrm{~cm}^{-1}$ and $1600 \mathrm{~cm}^{-1}$, which are the characteristic peaks of the D band and the $\mathrm{G}$ band for carbon, respectively. ${ }^{33}$ The $\mathrm{D}$ and $\mathrm{G}$ bands of the RM-S/G composite are very weak, confirming that graphene is buried inside the RM-S/G due to the aggregation of graphene-coated nano-sulfur particles. After ball milling, the graphene sheets are exposed to the laser radiation and exhibit higher intensity of the D and G bands of carbon in the ballmilled RM-S/G. Due to the confinement and exfoliation of graphene inside the sulfur particles, electrons not only can strike the surface of the sulfur/graphene composite, but also can pass through the RM-S/G 
particles, and thus, RM-S/G composite shows higher conductivity compared to hand-mixed sulfurgraphene composite, where the graphene only adheres to the surfaces of the sulfur particles.

The presence of carboxyl groups in both graphene and RM-S/G composite was confirmed by Fourier transform infrared (FTIR) spectroscopy. Figure S3 shows the FTIR spectra of graphene, RM-S/G composite, and sulfur. It is shown that both graphene and RM-S/G composite feature two sharp peaks at $1760 \mathrm{~cm}^{-1}$ and $2890 \mathrm{~cm}^{-1}$, which are characteristic peaks of $\mathrm{C}=\mathrm{O}$ stretching and $\mathrm{O}-\mathrm{H}$ stretching for carboxyl groups, while no characteristic peaks of $\mathrm{C}=\mathrm{O}$ stretching and $\mathrm{O}-\mathrm{H}$ stretching exist in the sulfur sample. The very sharp peak that appears at $2400 \mathrm{~cm}^{-1}$ in sulfur is attributed to the symmetric stretching of water $\left(\mathrm{H}_{2} \mathrm{O}\right)$ that comes from moisture. It is important to note here that the intensity of the O-H stretching-peak is decreased after the formation of RM-S/G composite and that the peak intensity decreases even further after ball milling. The breakage of hydrogen bonds is responsible for this. The lower the amount of hydrogen bond formation, the lower the intensity of the O-H stretching-peak will be. These carboxyl groups play a pivotal role in the exfoliation and the uniform dispersion of graphene in aqueous solution, as well as the bonding of lithium polysulfide onto graphene to stabilize the capacity during charge/discharge cycling.

\section{Electrochemical performance of RM-S/G composite}

The electrochemical performance of the RM-S/G composite was evaluated by both cyclic voltammetry and galvanostatic charge-discharge cycling. The cyclic voltammograms of RM-S/G composite in Figure 4a show two reduction peaks and one oxidation peak, with a small deviation in intensity with increasing cycle number. The first reduction peak appearing at 2.3-2.4 $\mathrm{V}$ is related to the change from elemental sulfur to long chain lithium polysulfides $\left(\mathrm{Li}_{2} \mathrm{~S}_{n}, n \geq 4\right)$, and the second reduction peak appearing at 1.9-2.0 $\mathrm{V}$ reflects the reduction of long chain lithium polysulfides to short chain lithium polysulfides $\left(\mathrm{Li}_{2} \mathrm{~S}_{n}, n<\right.$ 4), which is in agreement with the two plateaus of RM-S/G composite in the galvanostatic charge/discharge profiles in Figure $4 b .{ }^{34}$ In the charging profile, a small bump is observed at $2.3 \mathrm{~V}$ which 
later disappears with cycling, the position of which resembles the activation energy of polysulfide formation from $\mathrm{Li}_{2} \mathrm{~S}$. For the first cycle, the energy barrier is quite high, but in the following cycles, it is reduced significantly due to the presence of polysulfides that were formed in the previous cycle. It is wellestablished that the presence of trace amounts of polysulfides significantly reduces the activation barrier of $\mathrm{Li}_{2} \mathrm{~S}^{35-36} \mathrm{It}$ is important to note here that the reduction peak represented by a small bump at $1.7 \mathrm{~V}$ in the first two cycles of cyclic voltammograms $(\mathrm{CVs})$ is due to the reduction of $\mathrm{LiNO}_{3}$ salt, which can help to form a stable solid electrolyte interphase (SEI) on the lithium metal surface, ${ }^{37}$ thus reducing the shuttle reaction. The cycling behaviours of RM-S/G composite and hand-milled sulfur/graphene composite at a current density of $0.1 \mathrm{C}$ are shown in Figure 4c. Both the hand-milled sulfur-graphene composite and the RM-S/G composite cathodes consist of $6 \mathrm{wt} \%$ graphene, $34 \mathrm{wt} \%$ carbon black, $50 \mathrm{wt} \%$ sulfur, and 10 wt\% poly(vinylidene fluoride) (PVDF). On the other hand, commercial sulfur contains no graphene, but the sulfur content remains the same $(\sim 50 \mathrm{wt} \%)$. All three sulfur cathodes show typical charge/discharge behaviour with two plateaus at 2.4 and $2.1 \mathrm{~V}$. The RM-S/G composite, however, shows much higher capacity and cycling stability than the hand-milled sulfur/graphene composite. The hand-milled sulfur/graphene composite cathode shows an initial discharge capacity of $587 \mathrm{mAh} / \mathrm{g}$ (based on sulfur), which drops to $103 \mathrm{mAh} / \mathrm{g}$ after 200 cycles, representing $17.5 \%$ of the initial capacity. RM-S/G composite shows a much higher initial discharge capacity of $914 \mathrm{mAh} / \mathrm{g}$ (based on sulfur) and retains discharge capacity of $731 \mathrm{mAh} / \mathrm{g}$ after 200 cycles. The capacity retention of RM-S/G composite (around $80 \%$ ) is $62 \%$ higher than that of the hand-milled composite. The increased discharge capacity and capacity retention are due to the better exfoliation and adhesion of graphene in the sulfur particles, which not only increases the active material utilization, but also reduces the shuttle phenomenon. In addition, the RM-S/G composite shows excellent Coulombic efficiency of more than $99 \%$. 

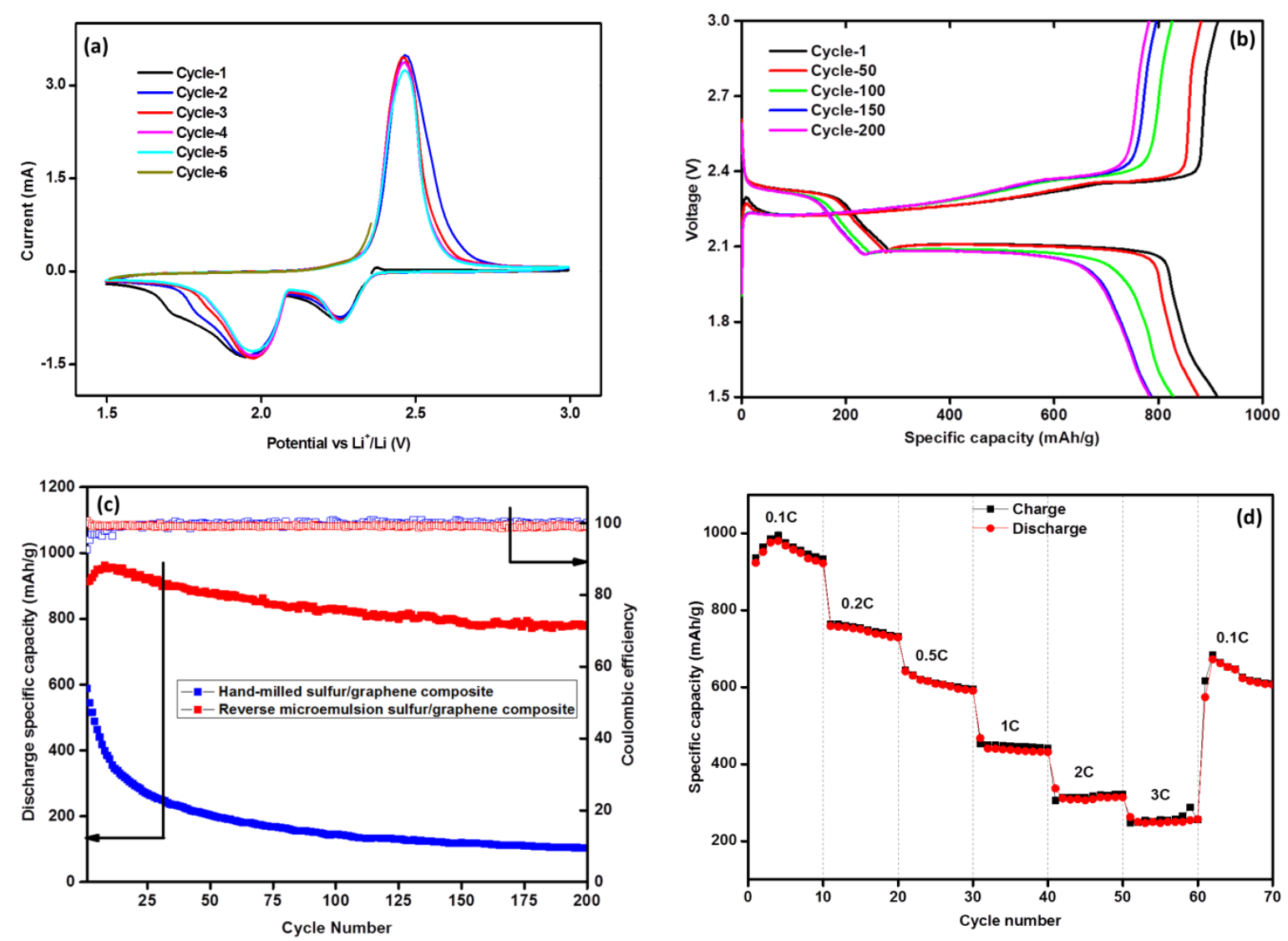

Figure 4. Electrochemical performance for low loading $\left(1-2 \mathrm{mg} / \mathrm{cm}^{2}\right)$ of $\mathrm{RM}-\mathrm{S} / \mathrm{G}$ composite on $\mathrm{Al}$ current collector: a) cyclic voltammograms of RM-S/G composite for the first 6 cycles at a scan rate of $0.1 \mathrm{mV} \mathrm{s}^{-1}$; b) galvanostatic charge-discharge curves for selected cycles of RM-S/G composite at $0.1 \mathrm{C}$; c) cycling performance of RM-S/G composite and hand-milled sulfur/graphene composite at a current density of $0.1 \mathrm{C}$; and d) rate capability of RM-S/G composite at different current densities.

The RM-S/G composite also show superior rate performance (Figure 4d), and even at the higher current density of $3 \mathrm{C}(5.025 \mathrm{~A} / \mathrm{g})$, the RM-S/G composite cathode can still deliver $250 \mathrm{mAh} / \mathrm{g}$ of discharge capacity. It has been calculated that, to surpass the current Li-ion technology, it is necessary to load more than $4 \mathrm{mg} / \mathrm{cm}^{2}$ of active material in a cathode ${ }^{38}$. With the conventional aluminum (Al) foil current collector, it is hard to load such a large amount of sulfur because the large volume changes of S/C composite will easily delaminate the thick S/C coating film on Al. A three-dimensional (3-D) 
interconnected conductive network such as carbon cloth has a large accessible surface area with high electrical conductivity, and can accommodate and utilize high amounts of active material. Recent reports 39-41 demonstrated that a 3-D network-structured carbon-cloth current collector can load larger amounts of active material while maintaining higher electrical conductivity, thermal stability, and structural integrity. The present 3-D interconnected carbon cloth for sulfur cathode is only used to physically block the highorder polysulfides, however, while maintaining the transport of electrons and ions during charging and discharging of the battery. Recently, Yuan et al. ${ }^{42}$ reported that heteroatom-doped (boron and nitrogen) carbon powders can enhance the cycling performance and stability of the Li/S system by minimizing the polysulfide shuttle phenomenon. Here, to increase the active material content as well as improving the cycling performance, we have introduced boron, nitrogen-doped carbon cloth as the current collector and active material host.
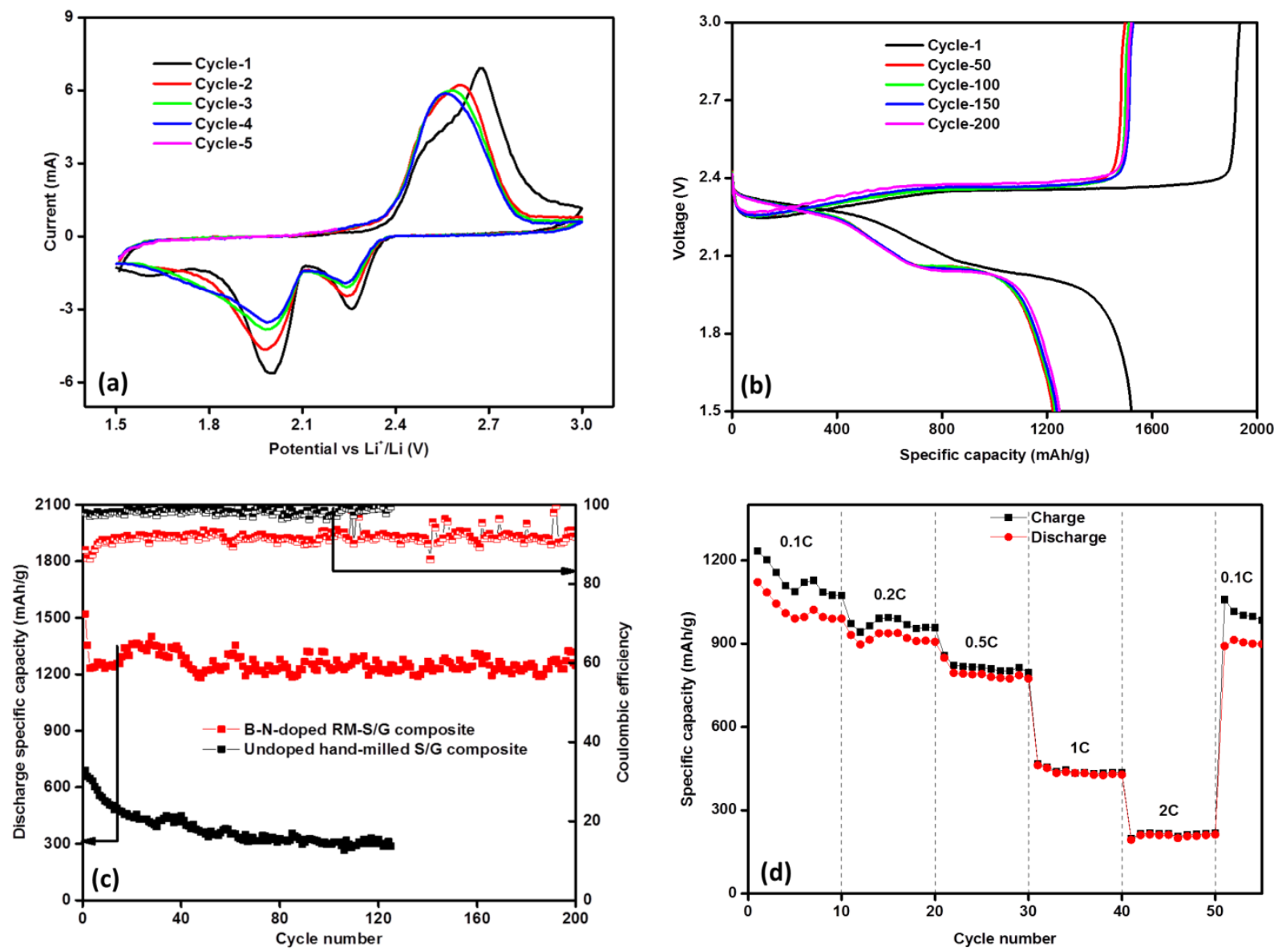
Figure 5. Electrochemical performance of RM-S/G composite loaded on boron, nitrogen-doped carbon cloth: a) cyclic voltammograms for the first 5 cycles of doped-RM-S/G composite at a scan rate of 0.1 $\mathrm{mV} \mathrm{s}^{-1}$; b) galvanostatic charge-discharge curves for selected cycles of doped-RM-S/G composite at 0.1 $\mathrm{C}$; c) cycling performance of B,N-doped RM-S/G composite and hand-milled undoped-sulfur/graphene in functionalized carbon cloth at a current density of $0.1 \mathrm{C}$; d) rate capability of doped-RM-S/G composite at different current densities.

Figure S4a shows the morphology RM-S/G composite-loaded B,N-doped carbon cloth, and Figure S4b shows the energy dispersive spectroscopy (EDS) mapping of B,N-doped carbon cloth, which confirms the presence of boron and nitrogen in the carbon cloth. The boron and nitrogen come from the tetrafluoroborate anion and the 1-ethyl-3-methylimidazolium cation, respectively. Figure S4a also shows the interaction between the RM-S/G composite and the carbon cloth, which firmly adhere to each other and compose a stable 3-D interconnected network. It is expected that this RM-S/G composite loaded on boron, nitrogen-doped carbon cloth will show better electrochemical performance along with high active material loading.

Figure 5 shows the electrochemical performance of the RM-S/G-composite-loaded B,N-doped carbon cloth cathode, where each cathode contains more than eight milligrams of active materials $\left(\sim 8-9 \mathrm{mg} / \mathrm{cm}^{2}\right)$. The CV curves in Figure 5a show two well-known reduction peaks and one oxidation peak. In the first cycle in Figure 5a, a big shoulder is observed on the oxidation peak, which is due to the lack of contact of the active materials with the electrolyte, which slows the oxidation process, giving rise to a broad shoulder in the oxidation curve rather than a sharp peak. After the first cycle, the electrolyte may have sufficient contact with the sulfur particles, which facilitates oxidation process, and for this reason, the broad shoulder disappears. It is also important to mention here that a similar phenomenon is not observed in Figure 4a, where a low amount of active materials $\left(1-2 \mathrm{mg} / \mathrm{cm}^{2}\right)$ was used in each electrode compared to Figure-5a, where around $8-9 \mathrm{mg} / \mathrm{cm}^{2}$ active materials were used. The low amount of active materials certainly reacts and quickly establishes contact with the electrolyte, so no broad shoulder was observed in 
Figure $4 \mathrm{a}$. The corresponding two discharge plateaus and one charge plateau were observed in the galvanostatic discharge-charge curves. Both the anodic and the cathodic current increased significantly compared to Figure 4a, which confirms the high loading of active materials and their utilization. The cycling performance in Figure $5 \mathrm{c}$ shows that, even at the higher loading of $9 \mathrm{mg} / \mathrm{cm}^{2}$, a specific discharge capacity of $1256 \mathrm{mAh} / \mathrm{g}$ was still maintained after 200 cycles at a current density of $0.1 \mathrm{C}$, corresponding to $99 \%$ capacity retention of the second cycle capacity. It is important to mention here that there is fluctuation in capacity with cycle numbers. The usage of different amounts of active materials, as well as the polysulfide confinement by the lone pair electrons of boron and nitrogen, may responsible for this phenomenon. In every cycle, there may be some differences in usage of active materials and polysulfide confinement that result in fluctuation in discharge capacity. In sharp contrast, the hand-milled sulfur/graphene composite cathode loaded in B,N-doped carbon cloth exhibits a quick capacity decay to $300 \mathrm{mAh} / \mathrm{g}$ after 100 cycles, with capacity retention of $40 \%$ at $0.1 \mathrm{C}$ current density due to the high sulfur loading. It can be deduced from the cycling performance that the doped 3-D carbon cloth and the reverse microemulsion method make a significant contribution to achieving higher capacity and better capacity retention. The rate performance of the RM-S/G-composite-loaded, B,N-doped carbon cloth cathode (Figure 5d) also shows that, even at higher current density, this cathode can deliver acceptable discharge capacity and can regain its capacity when low current density is restored.

For sulfur cathode with high active material content (generally more than $5 \mathrm{mg} / \mathrm{cm}^{2}$ ), precipitation of the sulfur active material from the current collector is observed due to loss of contact between the current collector and the active material. This sulfur is eventually deposited on the Li anode, which increases the internal impedance of the cell ${ }^{43}$. To analyse this, electrochemical impedance spectroscopy (EIS) was used to measure the evolution of impedance during charge/discharge cycling. Figure S5 shows EIS curves of RM-S/G composite-loaded B,N-doped carbon cloth cathode in the discharged state. The EIS curves show a depressed semicircle followed by an inclined straight line, which reflect the charge transfer resistance and lithium ion diffusion, respectively. It can be seen from the EIS curves that the impedance remains 
stable over 100 cycles, which indicates that the precipitation of active materials into the electrolyte was effectively supressed, with the active materials maintaining firm adhesion to the carbon cloth.

\section{CONCLUSION:}

Microsized carboxylated-graphene/sulfur particles formed by aggregation of primary nano-S/graphene particles were synthesized using a reverse microemulsion method, and the resultant carboxylatedgraphene sheets could effectively absorb both the sulfur and high-order polysulfides. This synthesized RM-S/G composite showed a very high initial discharge capacity of $914 \mathrm{mAh} / \mathrm{g}$ (based on sulfur), and retained discharge capacity of $731 \mathrm{mAh} / \mathrm{g}$ after 200 cycles. The electrochemical performance of the RMS/G composite was further enhanced by using B,N-doped 3-D carbon cloth as a current collector. The RM-S/G composite provided capacity of $1256 \mathrm{mAh} / \mathrm{g}$ after 200 cycles, with a capacity decay rate of $0.0127 \%$ per cycle at a current density of $0.1 \mathrm{C}$, even at $8 \mathrm{mg} / \mathrm{cm}^{2}$ of active material loading. This represents one of the best performances among all reported S/G composites at similar sulfur loadings.

\section{EXPERIMENTAL:}

Preparation of carboxylated-graphene/sodium polysulfide solution: $6.4 \mathrm{~g}$ commercial sulfur was added into $50 \mathrm{ml}$ of $2 \mathrm{M} \mathrm{Na}_{2} \mathrm{~S}$ aqueous solution. Then, the solution was stirred for several hours until all the sulfur reacted with the $\mathrm{Na}_{2} \mathrm{~S}$ to form $\mathrm{Na}_{2} \mathrm{~S}_{x}$. There was some unreacted sulfur residue powder in the solution, which was filtered out to obtain a clear red-colored $\mathrm{Na}_{2} \mathrm{~S}_{x}$ solution. $100 \mathrm{~g}$ carboxylated graphene was added into this solution, and it was sonicated for $10 \mathrm{~min}$ to form a homogeneously dispersed graphene/polysulfide solution. All the chemicals, the sulfur, the $\mathrm{Na}_{2} \mathrm{~S}$, and the carboxylated graphene were purchased from Sigma Aldrich. The following chemical reaction (reaction-1) occurred for the formation of polysulfides.

$(x-1) \mathrm{S}_{8}+8 \mathrm{Na}_{2} \mathrm{~S} \rightarrow 8 \mathrm{Na}_{2} \mathrm{~S}_{x}$ 
Preparation of microemulsions and graphene/sulfur composite: $30 \mathrm{~g}$ of a mixture of sorbitan monooleate $\left(\right.$ Span $\left.{ }^{\circledR} 80\right)$ and polyethylene glycol (PEG-20) sorbitan monooleate (Tween $\left.{ }^{\circledR} 80\right)$ in a ratio of 8:1, along with $10 \mathrm{ml} \mathrm{n}$-butanol, was added into $450 \mathrm{ml}$ of sulfur-saturated cyclohexane. Both Span 80 and Tween 80 act as surfactants, whereas n-butanol and cyclohexane act as a cosurfactant and the oil, respectively. Then, the mixture was homogenized by a Sonic Ruptor-400 ultrasonic homogenizer for 1 hour. The homogenized mixture was equally divided into two beakers to prepare two reverse microemulsion solutions. In the first beaker, $12.5 \mathrm{ml}$ of carboxylated-graphene-containing $\mathrm{Na}_{2} \mathrm{~S}_{x}$ was poured in, and the microemulsion was sonicated again for 10 to 15 minutes, whereas, in the second beaker, $12.5 \mathrm{ml}$ of $4 \mathrm{M} \mathrm{HCl}$ was added, and this microemulsion was also sonicated for 10 to 15 minutes. Finally, these two reverse microemulsions were mixed together and stirred for 2 to 3 hours to form the graphene/sulfur composite. The following reaction (reaction-2) occurred when the sulfur precipitated out and formed the graphene/sulfur composite.

$8 \mathrm{Na}_{2} \mathrm{~S}_{x}+16 \mathrm{HCl} \rightarrow 16 \mathrm{NaCl}+8 \mathrm{H}_{2} \mathrm{~S}+(x-1) \mathrm{S}_{8} \downarrow$

The composite was then separated by centrifugation at $5000 \mathrm{rpm}$ and repeatedly washed with acetone and water to remove all the oils and salts. A schematic illustration of this method is shown in Figure 1, and Figure S1 in the Supporting Information shows the photographs of the different steps. All the chemicals in this case were also purchased from Sigma and directly used without any purification.

Fabrication of boron- and nitrogen-doped carbon cloth: For the synthesis of boron- and nitrogen-doped carbon cloth we followed Yuan's method for preparing boron, nitrogen doped graphene. ${ }^{42}$ To do so, small diameter $(5 \mathrm{~mm})$ carbon cloth discs were cut and submerged in1-ethyl-3methylimidazolium tetrafluoroborate $\left([\mathrm{Emim}] \mathrm{BF}_{4}\right)$ ionic liquid in an argon-filled glove box. Then, the fully soaked carbon cloths were put into a quartz boat and transferred into a furnace for heat treatment at $330{ }^{\circ} \mathrm{C}$ under vacuum. After the heat treatment, the carbon cloths were further annealed at $400{ }^{\circ} \mathrm{C}$ in argon to form boron- and nitrogen-doped carbon cloth. 
Fabrication of electrodes and coin cells: The aluminum-current-collector-based cathode was fabricated by using the carboxylated graphene-sulfur precipitated composite, carbon black, and polyvinylidene difluoride (PVDF). The PVDF was added in the amount of $10 \mathrm{wt} \%$, and the amount of carbon black was dependent on the amount of sulfur, which was maintained at $50 \mathrm{wt} \%$ of the total amount. The composite, carbon black, and PVDF mixture was manually mixed for 20 to 30 minutes with the addition of an appropriate amount of N-methyl-2-pyrrolidone (NMP). The obtained slurry was coated on $\mathrm{Al}$ foil to a thickness of 90 microns and was then dried at $50{ }^{\circ} \mathrm{C}$ for 24 hours under vacuum. Then, the electrode was cut into $10 \mathrm{~mm}$ diameter discs. Each $10 \mathrm{~mm}$ disc contained around $1 \mathrm{mg}$ of active materials (sulfur). The fabricated disc electrodes were dried again at $50{ }^{\circ} \mathrm{C}$ for a few hours before use. For the carbon-cloth current-collector-based cathode, the slurry was prepared with the addition of carbon black and PVDF, where the sulfur content was $80 \mathrm{wt} \%$ along with $10 \mathrm{wt} \%$ PVDF and $10 \mathrm{wt} \%$ graphene and carbon black. $5 \mathrm{~mm}$ diameter carbon cloth discs were dipped into the slurry and dried in a vacuum oven for 24 hours at $50{ }^{\circ} \mathrm{C}$. Each $5 \mathrm{~mm}$ diameter carbon cloth disc contained 7.5 to $8.5 \mathrm{mg}$ of sulfur. These discs were then directly used as cathode in the coin cells. The CR 2032 coin-type cells were assembled in an Ar-filled glove box, where discs of Li foil were used as the counter electrode and reference electrode. The electrolyte was prepared by dissolving $1 \mathrm{M}$ lithium bis(trifluoromethane sulfonyl)imide (LiTFSI) and $0.1 \mathrm{wt} \% \mathrm{LiNO}_{3}$ in co-solvents of 1,3-dioxolane (DOL) and 1,2-dimethoxyethane (DME), in a volume ratio of 1:1. A porous polypropylene film was used as the separator.

Characterization: To characterize the sulfur-graphene composite and Li-S cells, different analytical tools were used. For physical characterization of the composite, we conducted X-ray diffraction (XRD; Bruker Smart-1000, Bruker AXS Inc., USA, using Cu Ka radiation), Raman spectroscopy (Horiba Jobin Yvon Labram Aramis using a 532 nm diode-pumped solid-state laser), Fourier transform infrared spectroscopy (FTIR; NEXUS 670 FT-IR), thermogravimetric analysis (TGA; Netzsch STA 449F3, Germany, in an argon environment with a heating rate of $5{ }^{\circ} \mathrm{C} / \mathrm{min}$ ), and four probe conductivity measurements (Signatone SP4). For morphological analysis, scanning electron microscopy (SEM) and 
transmission electron microscopy (TEM) were conducted on a Hitachi SU-70 analytical SEM (Japan) and a JEOL (Japan) 2100F field emission TEM, respectively. The scanning electron microscope was also used for conducting large-area energy dispersive X-ray spectroscopy (EDS) mapping. For electrochemical performance evaluation of the Li-S cell, an automatic battery tester system (Land ${ }^{\circledR}$, China) was used at various current densities at room temperature within a conventional voltage window (1.5-3 V).

Electrochemical impedance spectroscopy (EIS) and cyclic voltammetry (CV) measurements were performed on a Gamry Reference 3000 Potentiostat/Galvanostat/ZRA with a scan rate of $0.1 \mathrm{mV} \mathrm{s}^{-1}$ (within a voltage window of $1.5 \mathrm{~V}$ to $3 \mathrm{~V}$ ), and for impedance analysis, a frequency range of $10 \mathrm{mHz}$ to $100 \mathrm{kHz}$ was applied. 


\section{ASSOCIATED CONTENT}

Supporting Information. A supporting information document is attached to this manuscript.

"This material is available free of charge via the Internet at http://pubs.acs.org."

\section{AUTHOR INFORMATION}

\section{Corresponding Author}

* Prof. Chunsheng Wang

Department of Chemical and Biomolecular Engineering, University of Maryland, College Park, Maryland, 20742, United States.

Tel: 301-405-0352; Fax: 301-405-0523

E-mail: cswang@umd.edu

\section{Author Contributions}

The contributions of the authors to this work are as follows: Prof. Chunsheng Wang designed this work and the experiments, Mohammad Rejaul Kaiser prepared the electrodes and cells, conducted the tests, and wrote the manuscript, and all other authors revised and polished the manuscript.

\section{ACKNOWLEDGEMENTS}

This research has been conducted with the support of the Australian Government Research Training Program Scholarship. In addition, the authors gratefully acknowledge the financial 
support provided by the Excellerate Australia Professional Development Fund (Grant number:

AA2020CRC), an Australian Research Council (ARC) Discovery project (DP1601012627), and support from the Institute for Superconducting and Electronic Materials (ISEM), University of Wollongong, Australia, as well as Nanostructures for Electrical Energy Storage (NEES), an Energy Frontier Research Centre funded by the U.S. Department of Energy, Office of Science, Office of Basic Energy Sciences under Award No. DESC0001160. Wang, C. acknowledge Heilongjiang Province Natural Science Foundation (key project) （ZD2016-001), and Jiamusi University Technology Innovation Team（Cxtdpy-2016-01） for partially support this work.The authors also thank Silver, T. for critical reading of the manuscript.

\section{REFERENCES}

1. Gur, I.; Sawyer, K.; Prasher, R., Searching for a Better Thermal Battery. Science. 2012, $335,1454-1455$.

2. $\quad$ Bruce, P. G.; Freunberger, S. A.; Hardwick, L. J.; Tarascon, J.-M., Li-O 2 And Li-S Batteries with High Energy Storage. Nat Mater. 2012, 11, 19-29.

3. Ji, X.; Lee, K. T.; Nazar, L. F., A Highly Ordered Nanostructured Carbon-Sulphur Cathode for Lithium-Sulphur Batteries. Nat Mater. 2009, 8, 500-506.

4. $\quad$ Kaiser, M. R.; Wang, J.; Liang, X.; Liu, H.-K.; Dou, S.-X., A Systematic Approach To High and Stable Discharge Capacity for Scaling up The Lithium-Sulfur Battery. J Power Sources. 2015, 279, 231-237.

5. $\quad$ Liang, X.; Zhang, M.; Kaiser, M. R.; Gao, X.; Konstantinov, K.; Tandiono, R.; Wang, Z.; Liu, H.-K.; Dou, S.-X.; Wang, J., Split-Half-Tubular Polypyrrole@ Sulfur@ Polypyrrole Composite with a Novel Three-Layer-3D Structure as Cathode for Lithium/Sulfur Batteries. Nano Energy. 2015, 11, 587-599.

6. Takahashi, T.; Yamagata, M.; Ishikawa, M., A Sulfur-Microporous Carbon Composite Positive Electrode for Lithium/Sulfur and Silicon/Sulfur Rechargeble Batteries. Progress in Natural Science: Materials International. 2015, 25, 612-621.

7. $\quad$ Kaiser, M. R.; Liang, X.; Konstantinov, K.; Liu, H.-K.; Dou, S.-X.; Wang, J.-Z., A Facile Synthesis of High-Surface-Area Sulfur-Carbon Composites for Li/S Batteries. Chemistry - A European Journal. 2015, 21, 10061-10069.

8. $\quad$ Kaiser, M. R.; Liang, X.; Liu, H.-K.; Dou, S.-X.; Wang, J.-Z., A Methodical Approach for Fabrication of Binder-Free $\mathrm{Li}_{2} \mathrm{~S}-\mathrm{C}$ Composite Cathode with High Loading of Active Material for Li-S Battery. Carbon. 2016, 103, 163-171. 
9. Barghamadi, M.; Best, A. S.; Bhatt, A. I.; Hollenkamp, A. F.; Musameh, M.; Rees, R. J.; Ruther, T., Lithium-Sulfur Batteries-The Solution is in The Electrolyte, but is The Electrolyte A Solution? Energ Environ Sci. 2014, 7, 3902-3920.

10. Azimi, N.; Xue, Z.; Rago, N. D.; Takoudis, C.; Gordin, M. L.; Song, J.; Wang, D.; Zhang, Z., Fluorinated Electrolytes for Li-S Battery: Suppressing the Self-Discharge with an Electrolyte Containing Fluoroether Solvent. J Electrochem Soc. 2015, 162, A64-A68.

11. Hagen, M.; Dörfler, S.; Fanz, P.; Berger, T.; Speck, R.; Tübke, J.; Althues, H.;

Hoffmann, M. J.; Scherr, C.; Kaskel, S., Development and Costs Calculation of Lithium-Sulfur Cells with High Sulfur Load and Binder Free Electrodes. J Power Sources. 2013, 224, 260-268.

12. Jeddi, K.; Sarikhani, K.; Qazvini, N. T.; Chen, P., Stabilizing Lithium/Sulfur Batteries by a Composite Polymer Electrolyte Containing Mesoporous Silica Particles. J Power Sources. 2014, 245, 656-662.

13. Song, M.-K.; Zhang, Y.; Cairns, E. J., A Long-Life, High-Rate Lithium/Sulfur Cell: A Multifaceted Approach to Enhancing Cell Performance. Nano Lett. 2013, 13, 5891-5899.

14. Li, G.-C.; Li, G.-R.; Ye, S.-H.; Gao, X.-P., A Polyaniline-Coated Sulfur/Carbon Composite with an Enhanced High-Rate Capability as a Cathode Material for Lithium/Sulfur Batteries. Advanced Energy Materials. 2012, 2, 1238-1245.

15. Wang, J.; Chew, S. Y.; Zhao, Z. W.; Ashraf, S.; Wexler, D.; Chen, J.; Ng, S. H.; Chou, S. L.; Liu, H. K., Sulfur-Mesoporous Carbon Composites in Conjunction with A Novel Ionic Liquid Electrolyte for Lithium Rechargeable Batteries. Carbon. 2008, 46, 229-235.

16. Wang, J. Z.; Lu, L.; Choucair, M.; Stride, J. A.; Xu, X.; Liu, H. K., Sulfur-Graphene Composite for Rechargeable Lithium Batteries. J Power Sources. 2011, 196, 7030-7034.

17. Wang, J.; Chen, J.; Konstantinov, K.; Zhao, L.; Ng, S. H.; Wang, G. X.; Guo, Z. P.; Liu, H. K., Sulphur-Polypyrrole Composite Positive Electrode Materials for Rechargeable Lithium Batteries. Electrochim Acta. 2006, 51, 4634-4638.

18. Chen, R.; Zhao, T.; Lu, J.; Wu, F.; Li, L.; Chen, J.; Tan, G.; Ye, Y.; Amine, K., Graphene-Based Three-Dimensional Hierarchical Sandwich-type Architecture for HighPerformance Li/S Batteries. Nano Lett. 2013, 13, 4642-4649.

19. Lu, S.; Cheng, Y.; Wu, X.; Liu, J., Significantly Improved Long-Cycle Stability in HighRate Li-S Batteries Enabled by Coaxial Graphene Wrapping over Sulfur-Coated Carbon Nanofibers. Nano Lett. 2013, 13, 2485-2489.

20. Zhou, G.; Yin, L.-C.; Wang, D.-W.; Li, L.; Pei, S.; Gentle, I. R.; Li, F.; Cheng, H.-M., Fibrous Hybrid of Graphene and Sulfur Nanocrystals for High-Performance Lithium-Sulfur Batteries. ACS Nano. 2013, 7, 5367-5375.

21. Lin, T.; Tang, Y.; Wang, Y.; Bi, H.; Liu, Z.; Huang, F.; Xie, X.; Jiang, M., Scotch-TapeLike Exfoliation of Graphite Assisted With Elemental Sulfur and Graphene-Sulfur Composites for High-Performance Lithium-Sulfur Batteries. Energ Environ Sci. 2013, 6, 1283-1290.

22. Xu, C.; Xu, B.; Gu, Y.; Xiong, Z.; Sun, J.; Zhao, X. S., Graphene-Based Electrodes for Electrochemical Energy Storage. Energ Environ Sci. 2013, 6, 1388-1414.

23. Bagwe, R. P.; Yang, C.; Hilliard, L. R.; Tan, W., Optimization of Dye-Doped Silica Nanoparticles Prepared Using a Reverse Microemulsion Method. Langmuir. 2004, 20, 83368342.

24. Capek, I., Preparation of Metal Nanoparticles in Water-In-Oil (W/O) Microemulsions. Advances in Colloid and Interface Science. 2004, 110, 49-74.

25. Yang, Y.; Gao, M. Y., Preparation of Fluorescent $\mathrm{SiO}_{2}$ Particles with Single CdTe Nanocrystal Cores by the Reverse Microemulsion Method. Adv Mater. 2005, 17, 2354-2357. 
26. Koole, R.; van Schooneveld, M. M.; Hilhorst, J.; de Mello Donegá, C.; Hart, D. C.; van Blaaderen, A.; Vanmaekelbergh, D.; Meijerink, A., On the Incorporation Mechanism of Hydrophobic Quantum Dots in Silica Spheres by a Reverse Microemulsion Method. Chemistry of Materials. 2008, 20, 2503-2512.

27. Gibaud, S.; Attivi, D., Microemulsions for Oral Administration and Their Therapeutic Applications. Expert Opinion on Drug Delivery. 2012, 9, 937-951.

28. Lagourette, B.; Peyrelasse, J.; Boned, C.; Clausse, M., Percolative Conduction in Microemulsion Type Systems. Nature. 1979, 281, 60-62.

29. Meyer, B., Elemental Sulfur. Chemical Reviews. 1976, 76, 367-388.

30. Davies, R.; Graham, D. E.; Vincent, B., Water-Cyclohexane-“Span 80"-“Tween 80” Systems: Solution Properties and Water/Oil Emulsion Formation. J Colloid Interf Sci. 1987, 116, 88-99.

31. Kunieda, H.; Ishikawa, N., Evaluation of The Hydrophile-Lipophile Balance (HLB) of Nonionic Surfactants. II. Commercial-Surfactant Systems. J Colloid Interf Sci. 1985, 107, 122128.

32. Harvey, P. D.; Butler, I. S., Raman Spectra of Orthorhombic Sulfur at 40 K. Journal of Raman Spectroscopy. 1986, 17, 329-334.

33. Sadezky, A.; Muckenhuber, H.; Grothe, H.; Niessner, R.; Pöschl, U., Raman Microspectroscopy of Soot and Related Carbonaceous Materials: Spectral Analysis and Structural Information. Carbon. 2005, 43, 1731-1742.

34. $\quad$ Liang, X.; Wen, Z.; Liu, Y.; Zhang, H.; Huang, L.; Jin, J., Highly Dispersed Sulfur in Ordered Mesoporous Carbon Sphere as a Composite Cathode for Rechargeable Polymer Li/S Battery. J Power Sources. 2011, 196, 3655-3658.

35. Zu, C.; Klein, M.; Manthiram, A., Activated $\mathrm{Li}_{2} \mathrm{~S}$ as a High-Performance Cathode for Rechargeable Lithium-Sulfur Batteries. The Journal of Physical Chemistry Letters. 2014, 5, 3986-3991.

36. Meini, S.; Elazari, R.; Rosenman, A.; Garsuch, A.; Aurbach, D., The Use of Redox Mediators for Enhancing Utilization of $\mathrm{Li}_{2} \mathrm{~S}$ Cathodes for Advanced Li-S Battery Systems. $J$ Phys Chem Lett. 2014, 5, 915-918.

37. Zhang, S. S., Effect of Discharge Cutoff Voltage on Reversibility of Lithium/Sulfur Batteries with $\mathrm{LiNO}_{3}$-Contained Electrolyte. J Electrochem Soc. 2012, 159, A920-A923.

38. Manthiram, A.; Fu, Y.; Su, Y.-S., Challenges and Prospects of Lithium-Sulfur Batteries. Accounts of Chemical Research. 2013, 46, 1125-1134.

39. Dang, L.; Wei, C.; Ma, H.; Lu, Q.; Gao, F., Three-Dimensional Honeycomb-Like Networks of Birnessite Manganese Oxide Assembled by Ultrathin Two-Dimensional Nanosheets With Enhanced Li-Ion Battery Performances. Nanoscale. 2015, 7, 8101-8109.

40. Mao, S.; Lu, G.; Chen, J., Three-Dimensional Graphene-Based Composites for Energy Applications. Nanoscale. 2015, 7, 6924-6943.

41. Lingappan, N.; Van, N. H.; Lee, S.; Kang, D. J., Growth Of Three Dimensional FlowerLike Molybdenum Disulfide Hierarchical Structures on Graphene/Carbon Nanotube Network: An Advanced Heterostructure for Energy Storage Devices. J Power Sources. 2015, 280, 39-46. 42. Yuan, S.; Bao, J. L.; Wang, L.; Xia, Y.; Truhlar, D. G.; Wang, Y., Graphene-Supported Nitrogen and Boron Rich Carbon Layer for Improved Performance of Lithium-Sulfur Batteries Due to Enhanced Chemisorption of Lithium Polysulfides. Advanced Energy Materials. 2016, 6, 1501733. 
43. Qie, L.; Manthiram, A., A Facile Layer-by-Layer Approach for High-Areal-Capacity Sulfur Cathodes. Adv Mater. 2015, 27, 1694-1700. 


\section{Table of Content}

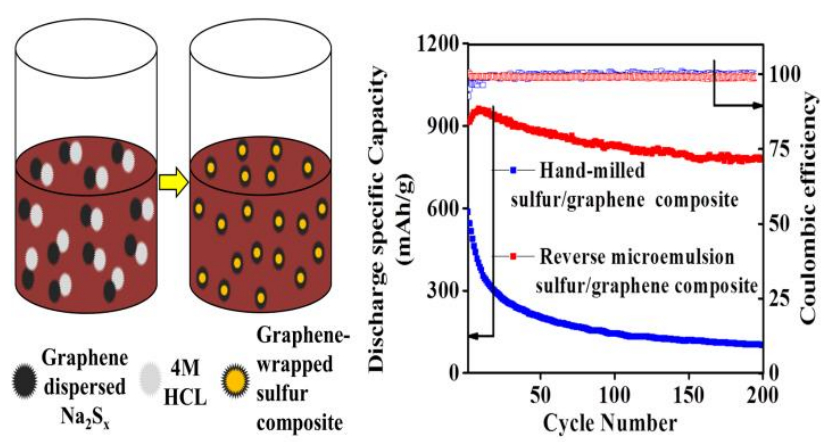




\section{Reverse Microemulsion Synthesis of Sulfur/Graphene Composite for Lithium/Sulfur Battery}

Mohammad Rejaul Kaiser ${ }^{a, b}$, Zhaohui Ma ${ }^{a}$, Xiwen Wang ${ }^{a}$, Fudong Han ${ }^{a}$, Tao Gao ${ }^{a}$, Xiulin Fan ${ }^{a}$, JiaZhao Wang ${ }^{b}$, Hua Kun Liu ${ }^{b}$, Shixue Dou ${ }^{b}$ and Chunsheng Wang ${ }^{a} *$

${ }^{a}$ Department of Chemical and Biomolecular Engineering, University of Maryland, College Park, Maryland, 20742, United States

${ }^{b}$ Institute for Superconducting and Electronic Materials, University of Wollongong, Wollongong, NSW 2522, Australia

*Correspondence address: $\underline{\text { sswang@umd.edu }}$

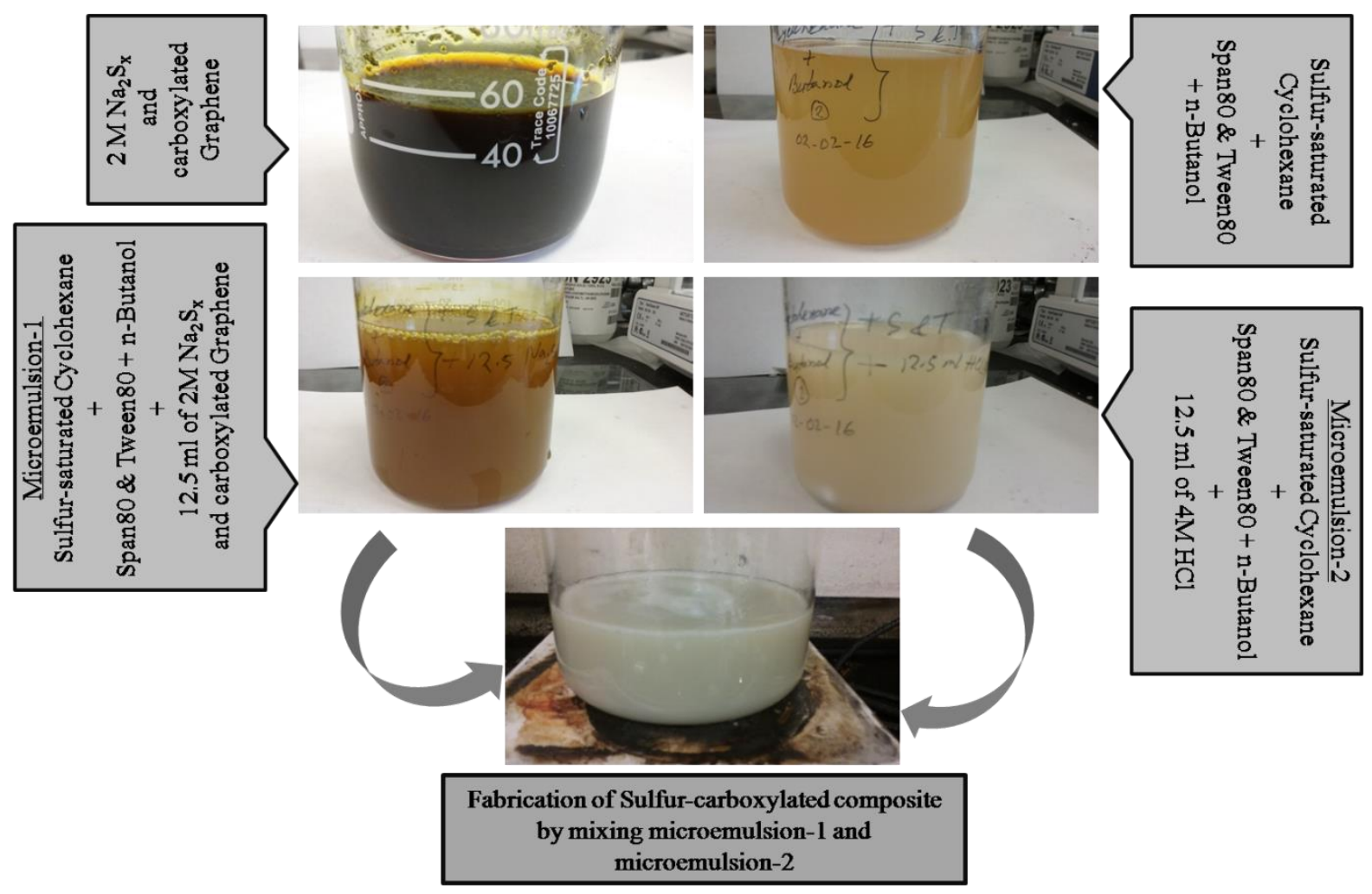

Figure S1: Photographs of the different steps in the reverse microemulsion method and synthesis of the sulfur-graphene composite. 


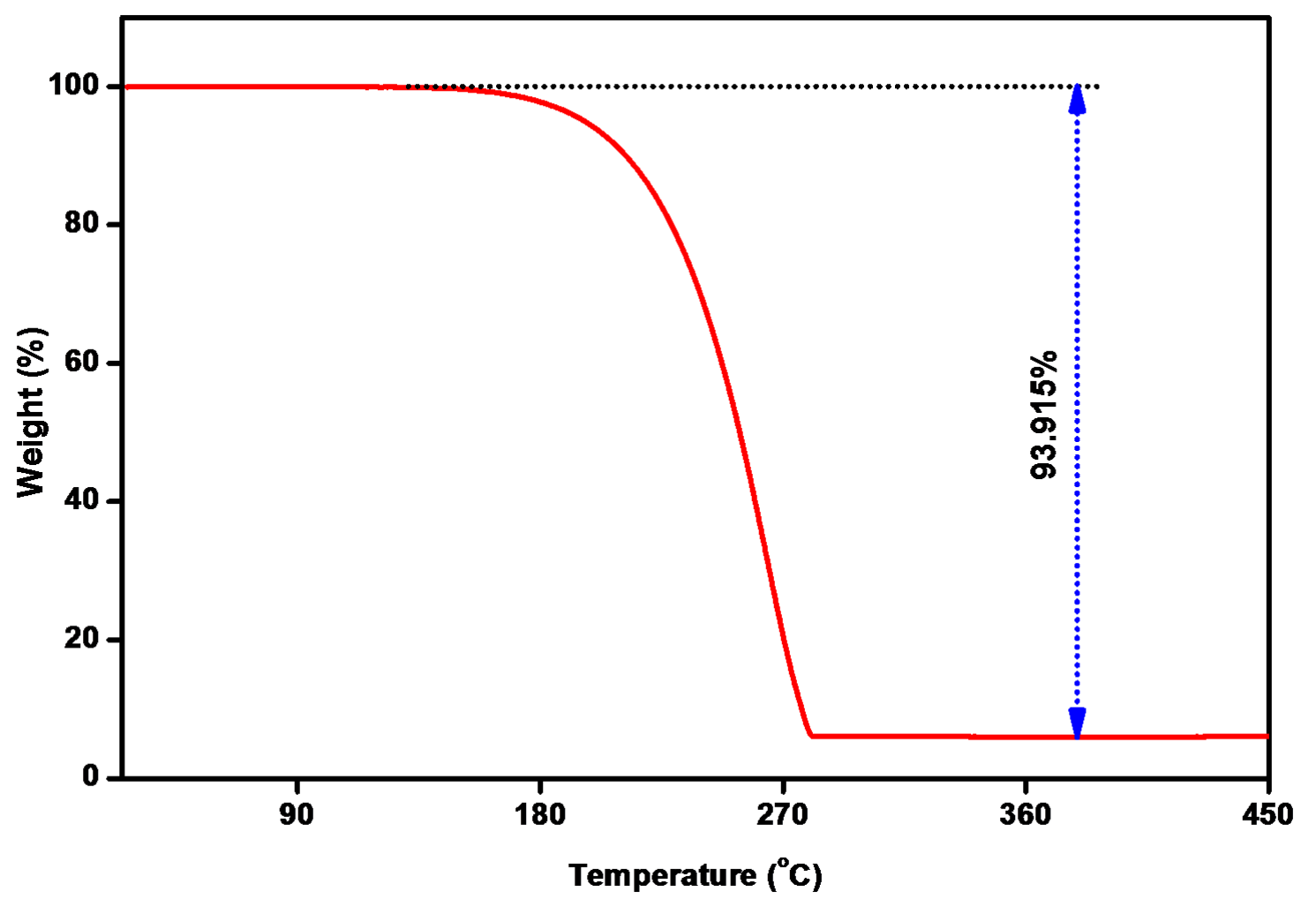

Figure S2: Thermogravimetric analysis (TGA) of sulfur-graphene composite. 


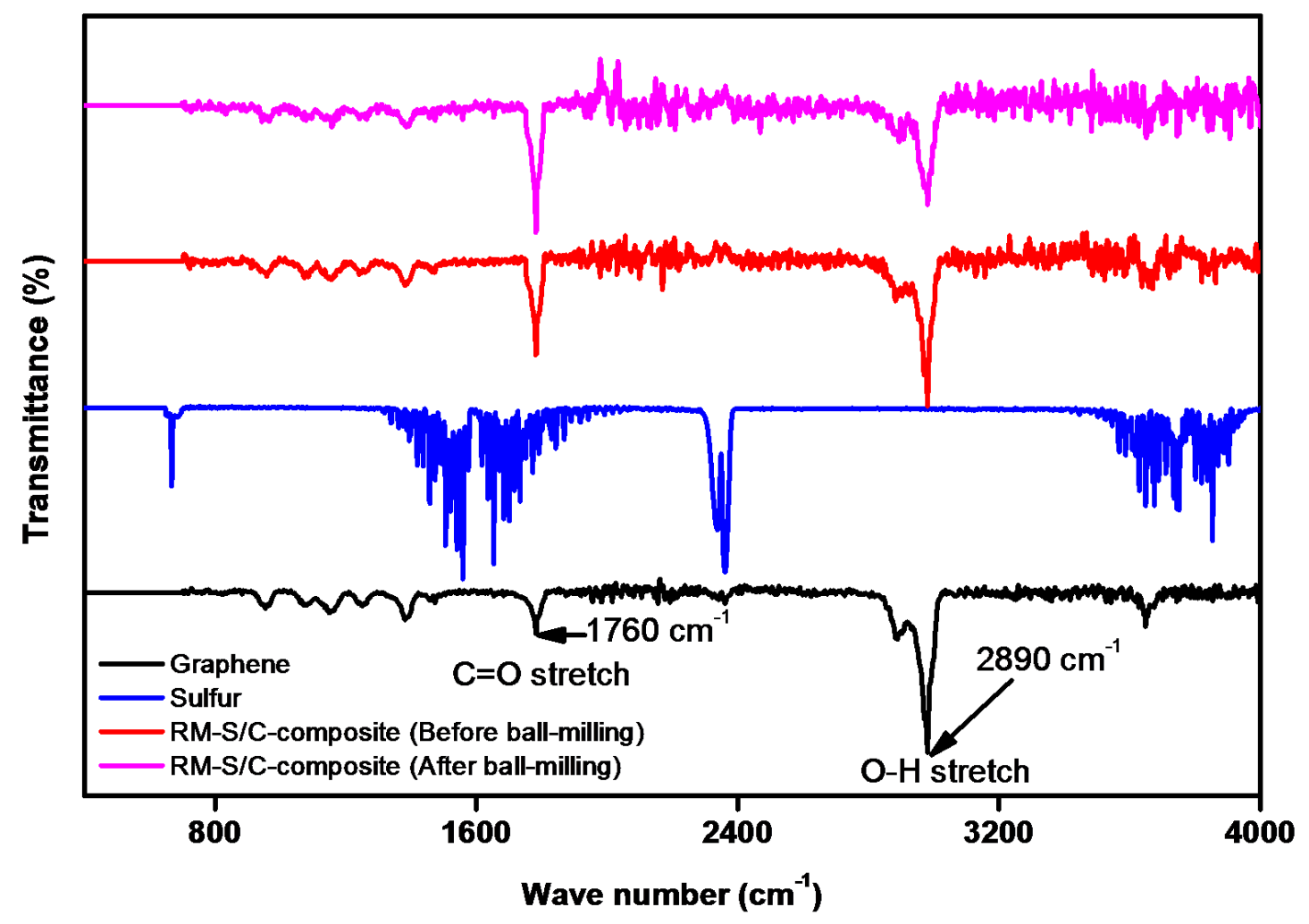

Figure S3: FTIR spectra of sulfur, graphene and RM-S/G composite. 


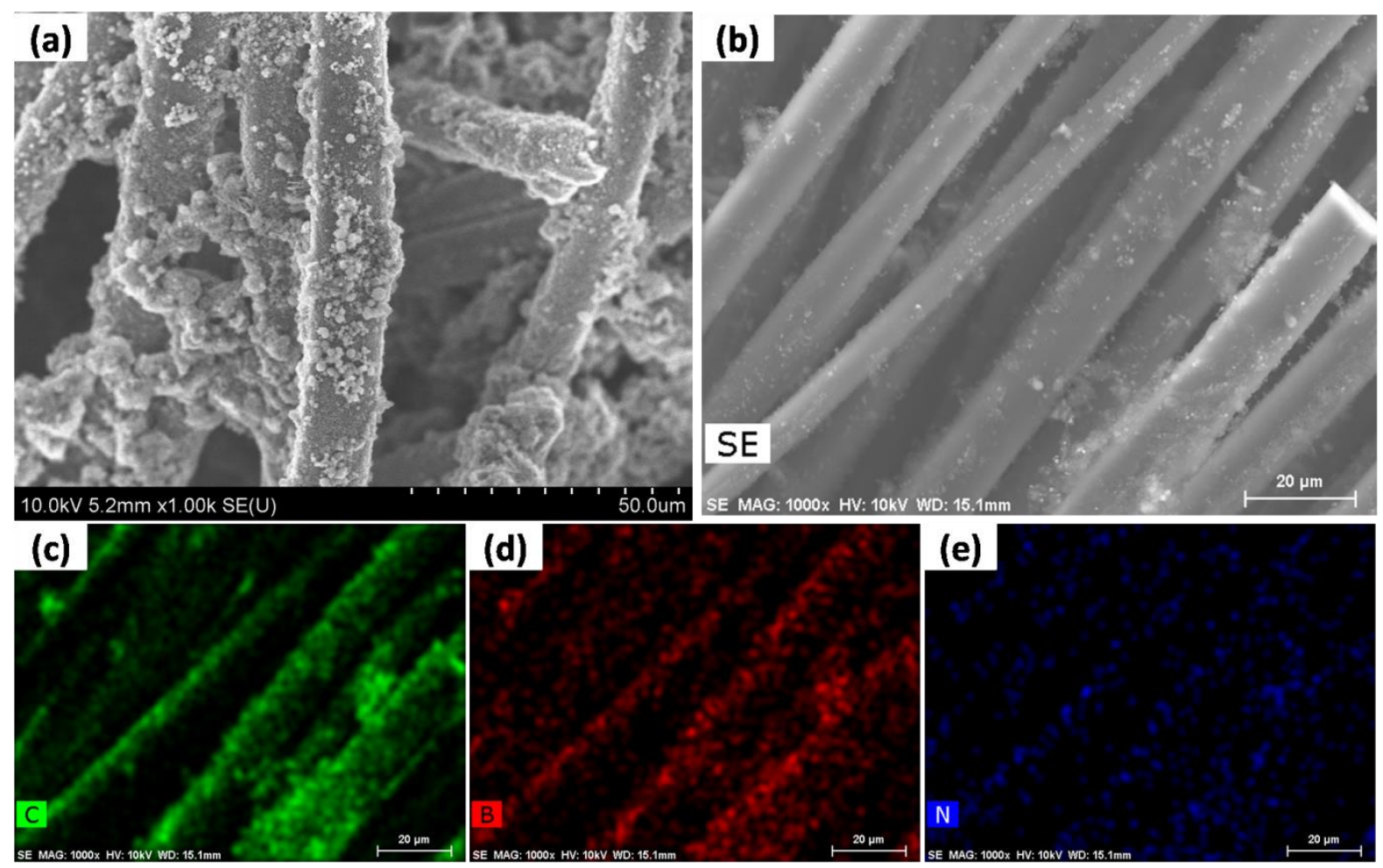

Figure S4: (a) SEM and (b-e) energy dispersive spectroscopy (EDS) analysis of boron, nitrogen-doped carbon cloth. 